NASA/TM-2001-211111

\title{
Use of Pressure Sensitive Paint for Diagnostics in Turbomachinery Flows With Shocks
}

Jan Lepicovsky

QSS Group, Inc., Brook Park, Ohio

Timothy J. Bencic

Glenn Research Center, Cleveland, Ohio 
Since its founding, NASA has been dedicated to the advancement of aeronautics and space science. The NASA Scientific and Technical Information (STI) Program Office plays a key part in helping NASA maintain this important role.

The NASA STI Program Office is operated by Langley Research Center, the Lead Center for NASA's scientific and technical information. The NASA STI Program Office provides access to the NASA STI Database, the largest collection of aeronautical and space science STI in the world. The Program Office is also NASA's institutional mechanism for disseminating the results of its research and development activities. These results are published by NASA in the NASA STI Report Series, which includes the following report types:

- $\quad$ TECHNICAL PUBLICATION. Reports of completed research or a major significant phase of research that present the results of NASA programs and include extensive data or theoretical analysis. Includes compilations of significant scientific and technical data and information deemed to be of continuing reference value. NASA's counterpart of peerreviewed formal professional papers but has less stringent limitations on manuscript length and extent of graphic presentations.

- TECHNICAL MEMORANDUM. Scientific and technical findings that are preliminary or of specialized interest, e.g., quick release reports, working papers, and bibliographies that contain minimal annotation. Does not contain extensive analysis.

- CONTRACTOR REPORT. Scientific and technical findings by NASA-sponsored contractors and grantees.
- CONFERENCE PUBLICATION. Collected papers from scientific and technical conferences, symposia, seminars, or other meetings sponsored or cosponsored by NASA.

- SPECIAL PUBLICATION. Scientific, technical, or historical information from NASA programs, projects, and missions, often concerned with subjects having substantial public interest.

- TECHNICAL TRANSLATION. Englishlanguage translations of foreign scientific and technical material pertinent to NASA's mission.

Specialized services that complement the STI Program Office's diverse offerings include creating custom thesauri, building customized data bases, organizing and publishing research results ... even providing videos.

For more information about the NASA STI Program Office, see the following:

- Access the NASA STI Program Home Page at http://www.sti.nasa.gov

- E-mail your question via the Internet to help@sti.nasa.gov

- Fax your question to the NASA Access Help Desk at 301-621-0134

- Telephone the NASA Access Help Desk at 301-621-0390

- Write to:

NASA Access Help Desk

NASA Center for AeroSpace Information 7121 Standard Drive

Hanover, MD 21076 


\section{Use of Pressure Sensitive Paint for Diagnostics in Turbomachinery Flows With Shocks}

Jan Lepicovsky

QSS Group, Inc., Brook Park, Ohio

Timothy J. Bencic

Glenn Research Center, Cleveland, Ohio

Prepared for the

15th International Symposium on Airbreathing Engines sponsored by the International Society for Airbreathing Engines Bangalore, India, September 2-7, 2001

National Aeronautics and

Space Administration

Glenn Research Center 


\section{Acknowledgments}

The work was sponsored by the NASA Glenn Research Center. The authors would like to thank Mrs. L. Shaw, Chief of the GRC Compressor Branch, for her continuous support.

This report is a preprint of a paper intended for presentation at a conference. Because of changes that may be made before formal publication, this preprint is made available with the understanding that it will not be cited or reproduced without the permission of the author.

Available from

NASA Center for Aerospace Information 7121 Standard Drive

Hanover, MD 21076
National Technical Information Service 5285 Port Royal Road Springfield, VA 22100 


\title{
USE OF PRESSURE SENSITIVE PAINT FOR DIAGNOSTICS IN TURBOMACHINERY FLOWS WITH SHOCKS
}

\author{
Jan Lepicovsky \\ QSS Group, Inc. \\ Brook Park, Ohio 44142 \\ and \\ Timothy J. Bencic \\ National Aeronautics and Space Administration \\ Glenn Research Center \\ Cleveland, Ohio 44135
}

\begin{abstract}
The technology of pressure sensitive paint (PSP) is well established in external aerodynamics. In internal flows in narrow channels and in turbomachinery cascades, however, there are still unresolved problems. In particular, the internal flows with complex shock structures inside highly curved channels present a challenge. It is not always easy and straightforward to distinguish between true signals and 'ghost' images due to multiple internal reflections in narrow channels. To address some of the problems, investigations were first carried out in a narrow supersonic channel of Mach number 2.5. A single wedge or a combination of two wedges were used to generate a complex shock wave structure in the flow. The experience gained in a small supersonic channel was used for surface pressure measurements on the stator vane of a supersonic throughflow fan. The experimental results for several fan operating conditions are shown in a concise form, including performance map points, midspan static tap pressure distributions, and vane suction side pressure fields. Finally, the PSP technique was used in the NASA transonic flutter cascade to compliment flow visualization data and to acquire backwall pressure fields to assess the cascade flow periodicity. A summary of shortcomings of the pressure sensitive paint technology for internal flow application and lessons learned are presented in the conclusion of the paper.
\end{abstract}

\section{Experimental Technique of Pressure Sensitive Paint}

The technique of pressure sensitive paint (PSP) is based on luminescent coatings, which are painted on flow containing walls, and excited by light of selected wavelengths. The excited paint emits light that is inversely proportional to the surface pressure. The emitted - the surface pressure map-is imaged with digital cameras (Refs. 1, 2). There are two basic methods of retrieving a pressure signal from emitted light. In the first one, the intensity method ("wind-off/wind-on"), the pressure at a point is determined from the ratio of the wind-off to windon recorded light intensities for continuous illumination. In the second one, the lifetime method, pressure is determined from the decay time of luminescence after the paint has been excited by illumination flashes (Ref. 3 ).

The PSP technique is now well established in external aerodynamics; the references are too numerous to be listed here. In internal flows in narrow channels, in turbomachinery, high-speed flow applications, and in applications with elevated non-uniform temperatures, however, there are still unresolved problems complicating the PSP use, accuracy, and reliability. The experience with PSP in internal aerodynamics and turbomachinery is rather limited (Refs. 4 through 9). In this paper, the NASA GRC experience with PSP in internal flows with complex shock structures is summarized. In all cases presented, the PSP intensity method was used. 


\section{Narrow Supersonic Channel of Mach Number 2.5}

A supersonic channel with a test section free stream Mach number of 2.5 was designed to provide a research tool for development work on flow diagnostic methods (Refs. 10 and 11). The channel, shown in Fig. 1, had a constant width of $25 \mathrm{~mm}$. The nozzle was designed for an exit Mach number of 2.5. The test section with a constant Mach number was over $800 \mathrm{~mm}$ long. The channel had large access windows in both sidewalls. One or two wedges could be inserted in the test section to generate a flow shock wave structure. Fig. 2 shows the PSP apparatus in front of the test channel.

In the first experiment (Ref. 12), the wall pressure distribution in the inlet section of the test channel was investigated. The acquired pressure map, shown in Fig. 3, indicates a rapid pressure drop in a circular fashion from the center of the nozzle throat. Immediately beyond the nozzle throat, the pressure falls faster along the upper and lower contour than along the nozzle centerline. As the flow moves into the area of the largest divergence, the flow along the centerline accelerates faster than the flow along the upper and lower curved walls and the pressure distribution across the channel height equalizes. The pressure difference along the channel height generates strong secondary flows in the initial portion of the channel. A wall boundary layer flow streamline pattern, shown in a photograph in Fig. 4, reveals the extent of the secondary flow. From the captured pattern, the maximum angle of the boundary layer streamline with

\section{PRESSURE}

SCALE [kPa]

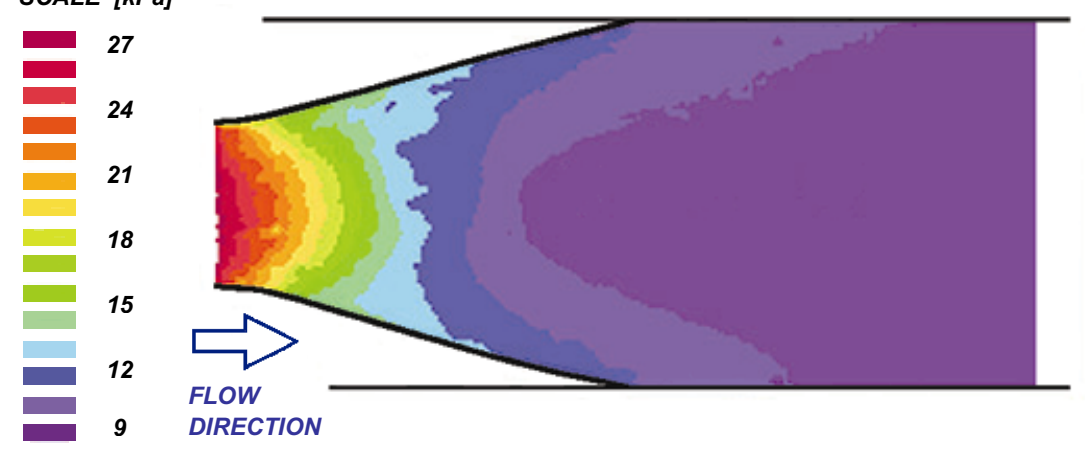

Fig. 3 Sidewall surface pressure map.

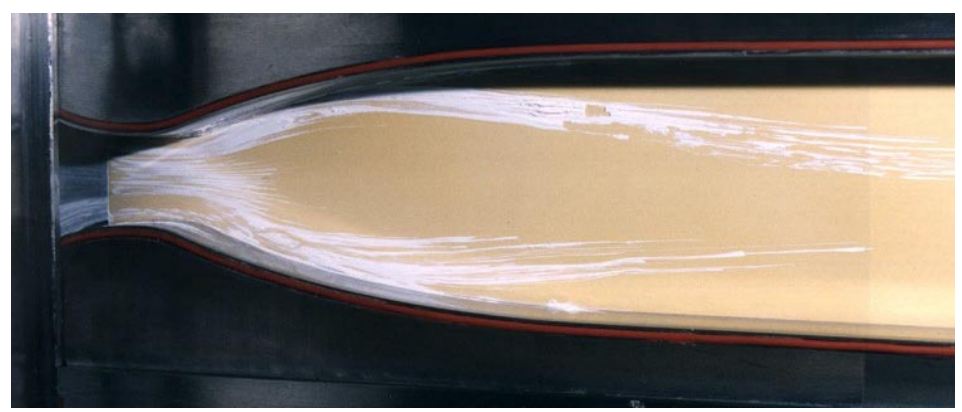

Fig. 4 Sidewall boundary layer flow pattern.

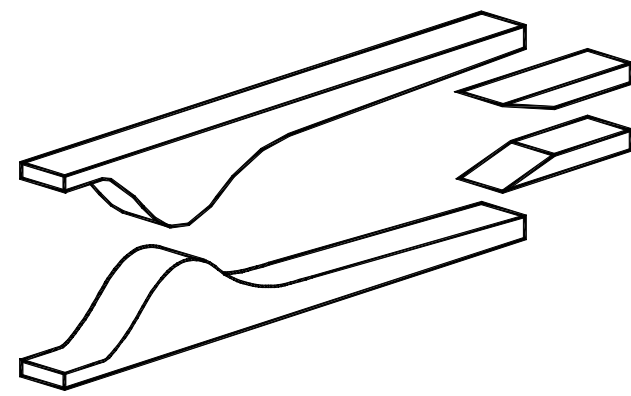

Fig. 1 Narrow supersonic channel with wedge-shock generators.

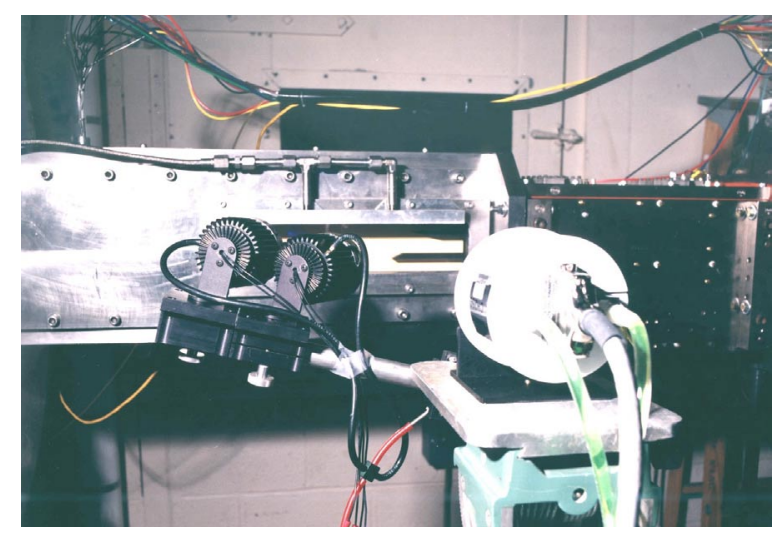

Fig. 2 PSP apparatus with the narrow supersonic channel.

respect to the main flow direction was estimated to be $6.0 \mathrm{dg}$. The velocity component perpendicular to the mean flow reaches up to $10 \%$ of the local axial velocity.

In the second experiment, a single 25- $d g$ wedge was inserted in the constant Mach number test section. The wedge generated an oblique shock that impinged on the channel sidewalls and generated a pattern of elevated static pressure in the region of the shock-wave/wall-boundarylayer interaction. The shadowgraph image of the oblique shock wave generated by the wedge in the flow is shown in Fig. 5. Fig. 6 shows the sidewall pressure pattern for the same test condition. The image of the shock was superimposed on the pressure data during postprocessing. At the wedge tip, the static pressure pattern is 'lagging' behind the shock. This is because the wedge does not extend up to the sidewalls but there is a gap of $3.6 \mathrm{~mm}$ between the wedge and the wall. Therefore the shock presence is felt on the sidewall a small distance downstream of 


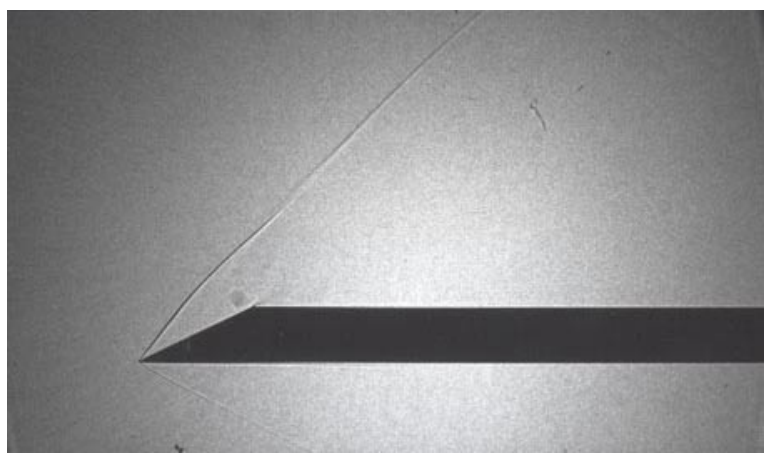

Fig. 5 Shadowgraph of an oblique shock wave for a single wedge.

the wedge tip. Due to shock/boundary-layer interaction the pressure 'hump' on the sidewall is quite wide, and thus the surface pressure measurement alone cannot determine the exact position of the shock in the flow.

Fig. 7 shows a shadowgraph of a complex shock wave pattern generated by two wedges in the flow. The structure is in a form of the Mach reflection triple point shock pattern. The pattern consists of a normal shock originating at the upper wedge vertex, the oblique shock attached to the lower wedge, and a reflected oblique shock. The slip surface originating at the triple point separates the subsonic flow behind the normal shock and the supersonic flow behind the reflected oblique shock. The accompanying static pressure field felt on the back wall is in Fig. 8. The regions of increased static pressure behind the shocks are clearly visible. The region with the highest pressure is just downstream of the triple point region. As in the previous case, exact position of the shocks cannot be determined from the pressure field alone even though shocks are very well defined in the flow.

A specific feature of the application of PSP to channel flows is the problem of possible signal misinterpretation due to signal reflections from neighboring walls (ghost images). The problem of internal reflections is dramatically demonstrated in Figs. 9 and 10 (Ref. 12). Fig. 9 shows a skewed view of the test section where the back wall was replaced by a glass window. No PSP was applied here. A mirror image of the wedge face can be clearly seen. Fig. 10 shows a similar situation, this time, however, the back wall is solid, and painted with PSP. The wedge front face is also painted; it appears white because the pressure level is outside of the selected scale. The PSP signal from the wedge face is superimposed on the signal from the solid wall (ghost image). In this case, the region of reflected signal is manifested as a region of elevated pressure on the sidewall. Clearly, if an

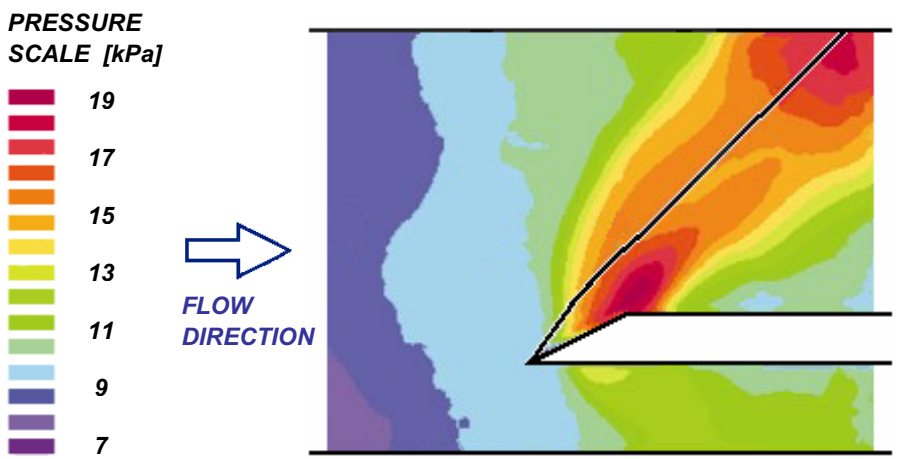

Fig. 6 Sidewall pressure map of the oblique-shock / wall interaction and superimposed shock shadowgraph.

experimenter was not aware of the PSP signal reflection, the sidewall pressure map interpretation would be completely false. The same flowfield was already shown in Fig. 6 where the observation angle was such that recording of reflected signals (ghost image) was suppressed.

In simple geometries and in situations where it is possible to arrange for observation angles perpendicular to the surfaces investigated, the danger of data contamination due to internal reflections is minimized. In many situations, particularly in turbomachinery applications, however, the

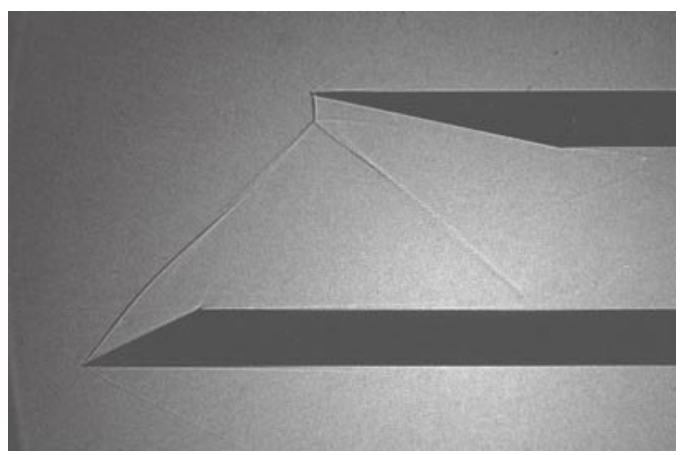

Fig. 7 Shadowgraph of a two-wedge shock wave pattern.

PRESSURE SCALE [kPa]

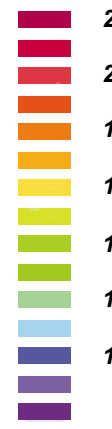

Fig. 8 Backwall pressure map of a shock pattern for two wedges. 

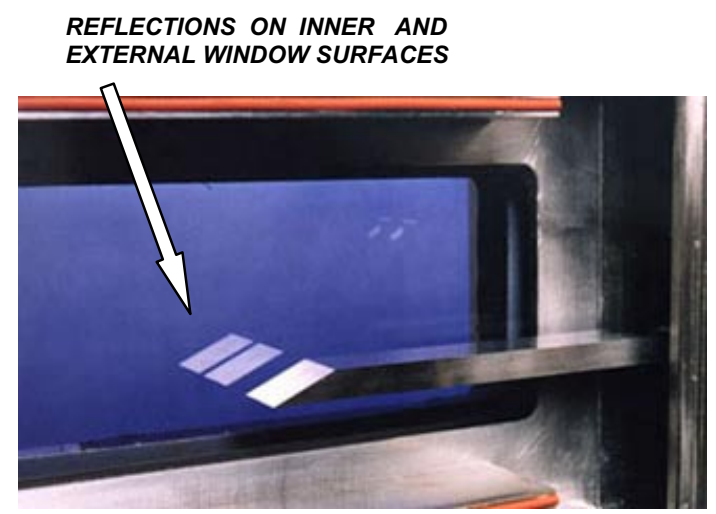

Fig. 9 Optical reflection of the wedge face on the channel backwall.

surfaces investigated can only be observed under oblique angles, the surrounding surfaces are very close and highly curved, and consequently the danger of ghost images and pressure map contamination is very high. There is no generic solution for eliminating ghost images and signal contamination in curved narrow channels. It is good practice to apply PSP to only one surface at a time and to paint remaining surfaces with antireflection coatings. If possible, the recording camera should be placed perpendicularly to the surface to be investigated. Finally, in situations where optical access allows only observation at oblique angles, two data sets should be recorded, each taken at different illumination and recording angles. Because the position of a ghost image depends on the observation angle, the pressure maps retrieved from the above mentioned two data sets will be identical within the experimental error band only if they are free of ghost images and therefore represent the true surface pressures.

\section{Stator of a Supersonic Throughflow Fan}

Pressure distributions on compressor or turbine blades are usually measured using static taps located along the blade surface, and therefore data is limited to several points only. An obvious advantage of the PSP technique is that the pressure field on the entire blade can be determined at once. The NASA experience with the application of PSP to stator vanes of a supersonic fan is described below.

A test setup of a PSP application for turbomachinery testing is shown in Fig. 11 (Ref. 13). The CCD camera and two blue light halogen lamps are in the foreground (camera in middle, halogen lamps are inside ribbed cooling jackets). The camera is facing an access window over a stator of a supersonic fan. Three stator vanes are visible in the access window. The suction side of the middle vane (the upper surface) was painted for testing.

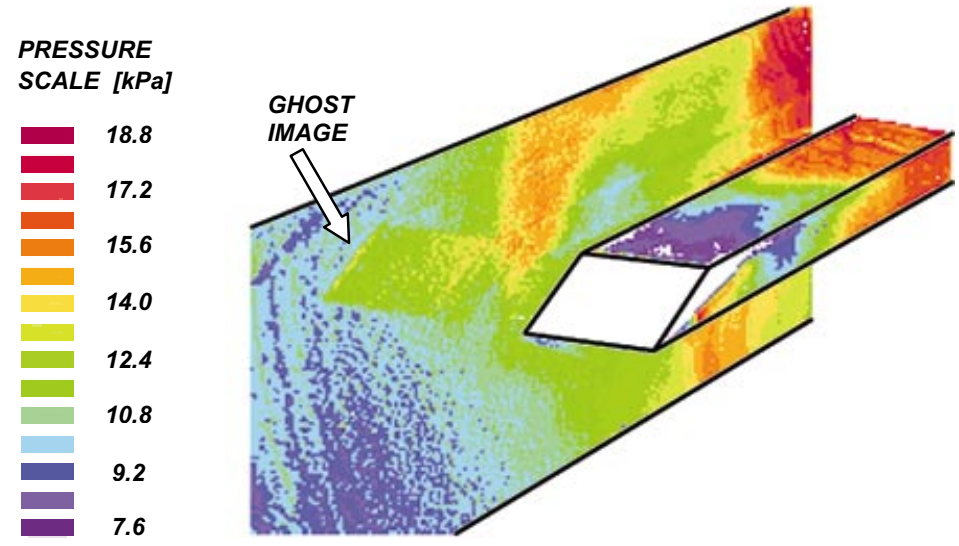

Fig. 10 PSP signal reflection of the wedge face pressure field on the backwall surface pressure map.

The air in the fan flows from right to left. Due to optical access limitations, the CCD camera records a skewed twodimensional image of the stator vane. An example of the vane suction surface as seen by the camera is shown in Fig. 12. The figure shows a map of computer color-coded distribution of gray levels of paint luminescence intensity relative to an average lavel.

The result in Fig. 12 must be modified in two ways to allow for direct comparison with analytical data. First, the intensity of emitted light must be converted to pressure units using a PSP calibration procedure. Second, the skewed view image of the stator vane must be converted to the meridional projection view that is customary in compressor designs. The signal conversion to pressures must take into account temperature changes as the tested turbomachine is operated because in general the PSP methodology assumes very small differences in surface temperatures between the reference and run images. Several approaches to this problem are discussed in Ref. 12. The transformation of skewed images into meridional projection is based on mathematical manipulation. The entire procedure is explained in detail in Ref. 14. The

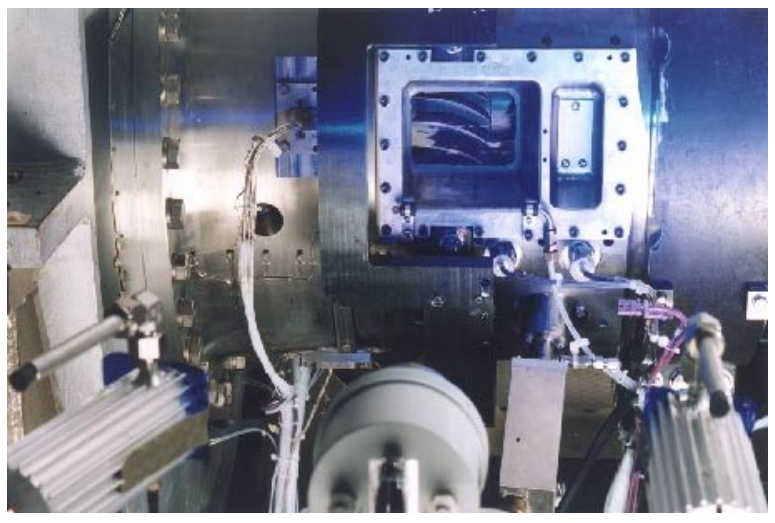

Fig. 11 PSP setup for turbomachinery application. 


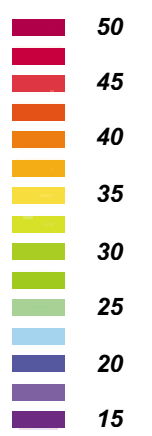

CAMERA VIEW

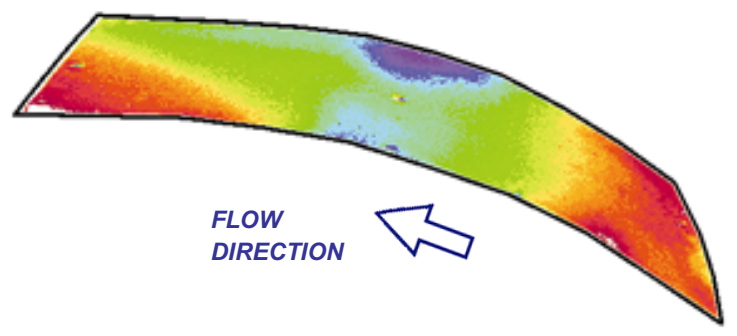

Fig. 12 Camera image of tested surface.

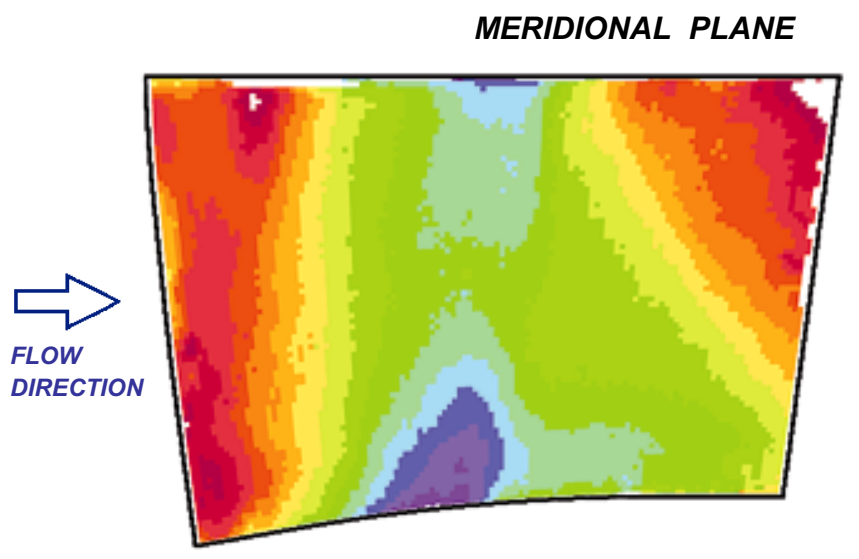

Fig. 13 Meridional plane suction-side vane-surface pressure field.

resulting pressure map after the image geometry transformation is shown in Fig. 13. The involved image processing affects the resulting spatial accuracy. The contour shape of the transformed image is within $2.0 \%$ of the sizes of the original hardware.

The experimental results for seven operating conditions of a supersonic single-stage fan are shown in concise form in Fig. 14 (Test Points A through G). Every test point is described by three diagrams arranged vertically. The top diagram shows the speed line; the large solid dot indicates the point of operation. The middle diagram shows the static pressure distribution on the vane suction side as measured by nine static taps located at mid span of the vane. Finally, the bottom diagram shows the pressure field map on the vane suction side as determined by the PSP technique. The black dots in the pressure field maps indicate locations of the static taps on the vane suction surface.

As the operating point is varied along the speed line from the near stall conditions (Test Point A) to a condition beyond choke (Test Point G), the midspan static pressure distributions change dramatically. As the back pressure drops, the mass flow rate increases, and pressure distribution exhibits a minimum at the throat region until choking occurs (Test Point E), after which, for further decrease of the back pressure, the minimum pressure occurs just ahead of a shock in the divergent portion of the channel. The PSP pressure field map for the conditions of Test Point E corresponds to the situation where the flow velocity in the throat region is nearly sonic. After the throat becomes choked, further drop in back pressure induces the formation of a shock wave in the channel, downstream of the channel throat (Test Point F). The shock wave, or at least its pressure-rise imprint on the vane suction side, is straight and oriented in the radial direction. Finally, for conditions well within the fan choke regime (Test Point $G$ ) the shock wave is located just upstream of the vane trailing edge. The shock wave is oriented mainly in the radial direction with some minor curvature near the hub endwall.

During the experiments, several problems were encountered that affected the reliability of the PSP technique in a turbomachinery environment and must be resolved for the PSP method to become a practical tool for experimental turbomachinery research. The most serious problems were: (1) a large drop in paint sensitivity due to oil mist contamination,
(2) inadequate paint adherence to the test surface, and (3) adverse effects of internal light reflections on data reliability ("ghost images").

Water condensation on the painted surface interrupts the testing only temporarily since after evaporation the paint recovers its sensitivity. The oil contamination is a more serious and permanent problem. Oil does not evaporate and leaves a permanent residue on the painted surface causing a dramatic drop in the PSP signal intensity. The only solution is to interrupt the test, strip the paint, and repaint the surface. Special care should be exercised to avoid oil leaks into the flow path.

Two paint erosion problems were observed. First, paint peeling occurred due to high shear stress and severe flow separation at some off-design and transitional operating conditions; second, paint erosion was caused by dust particles in the flow. To avoid erroneous data, testing should be terminated at the first sign of paint peeling, particularly if the intensity method is used. Even a partially stripped surface (a very small spot) changes the illumination distribution intensity causing a reduction in calibration accuracy, because the wind-off reference is no longer valid. Further, it can generate a false signal (ghost image), which contaminates the recorded pressure field. 

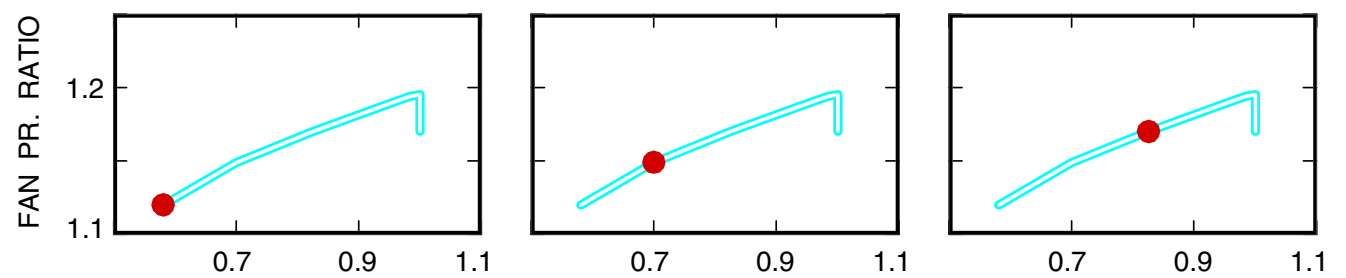

DIMENSIONLESS MASS FLOW RATE

DIMENSIONLESS MASS FLOW RATE
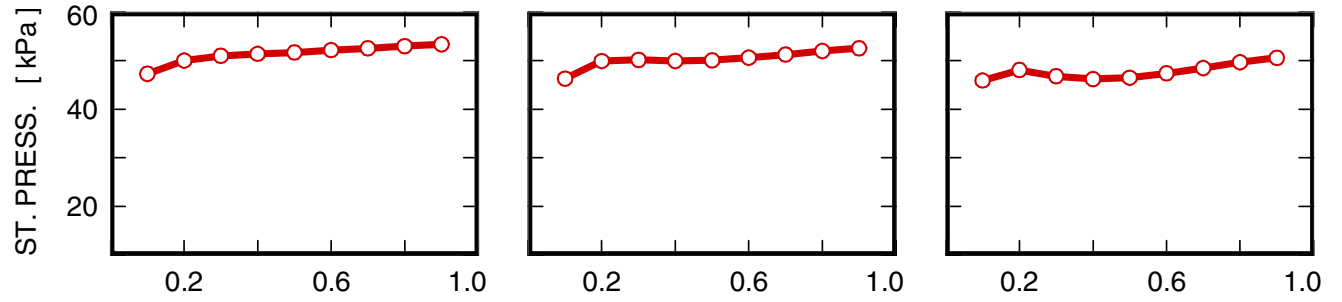

DIMENSIONLESS CHORD POSITION

DIMENSIONLESS CHORD POSITION

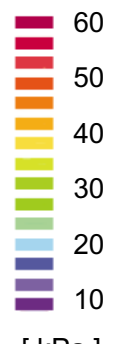

[ $\mathrm{kPa}$ ]

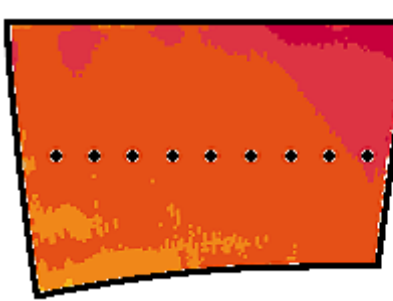

TEST POINT A

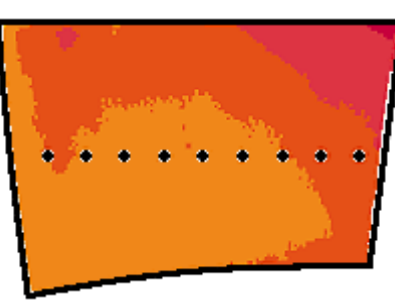

TEST POINT B

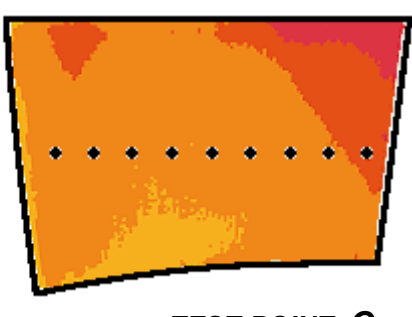

TEST POINT C
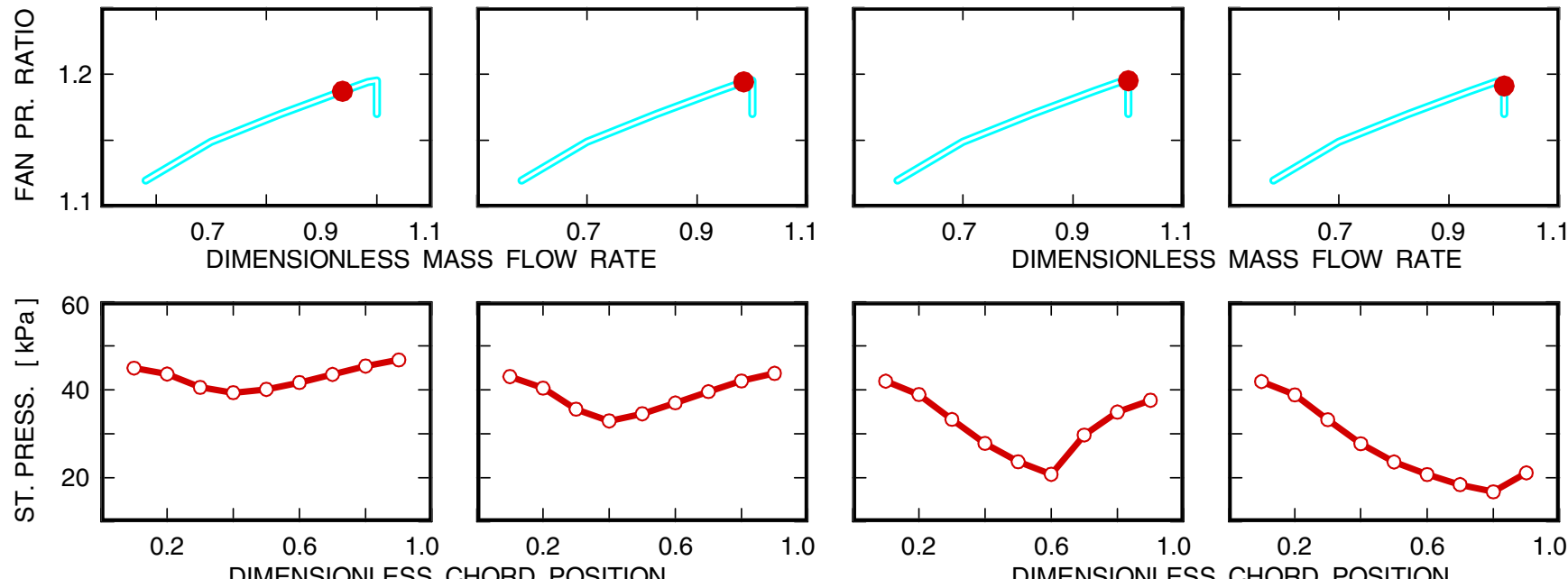

60
50
$=$
$=$
$=$
$=$
$=$
$=$

[ $\mathrm{kPa}$ ]

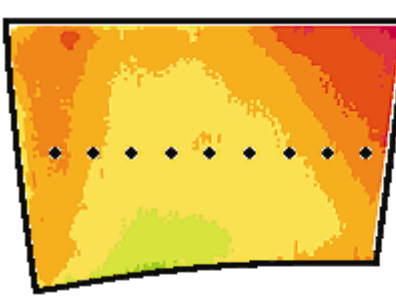

TEST POINT D

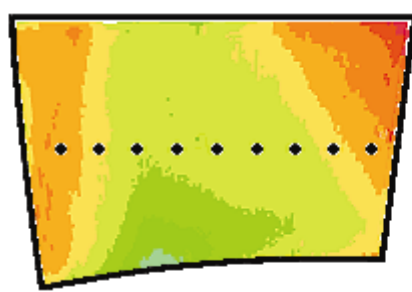

TEST POINT E

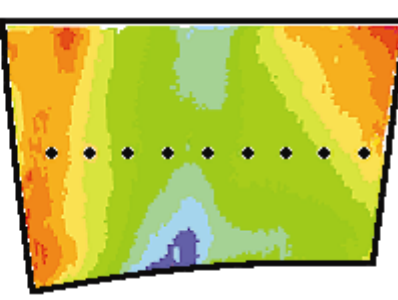

TEST POINT F

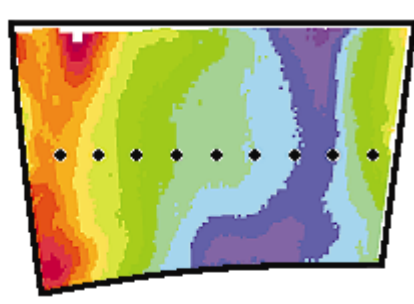

TEST POINT G

Fig. 14 Vane pressure field variation with fan operating conditions. 


\section{NASA Transonic Fan Cascade}

The NASA GRC Transonic Flutter Cascade is one of very few test facilities dedicated to the unsteady aerodynamics of oscillating airfoils (Ref. 15). The view of the cascade is shown in Fig. 15. The facility is used to provide data for modeling aerodynamics of blade stall flutter in a transonic fan. The facility combines a linear cascade wind tunnel with a high-speed drive system that imparts pitching oscillations to cascade blades. The main goal of the research conducted here is to determine unsteady loading of the blades under oscillations. The loading is determined by measuring unsteady pressures along the chord of the oscillating blades. At present, the unsteady pressure distributions are measured using miniature pressure transducers built in the blades. The major problems with the current arrangement are: (1) high cost of instrumentation, (2) fragility and short life time of miniature pressure transducers, (3) limited number of measurement stations, and (4) lack of data from the important part of the blade - the airfoil leading edge region where airfoils are too thin for transducers to be built in.

The PSP technique, in this particular application, would solve most of the major problems. There is, however, an important question of the frequency response of the pressure paints to fluctuating pressure. NASA GRC is carrying out a research effort to determine reliably the frequency range of available PSP. Until this question is satisfactorily answered, the use of PSP will be limited to steady state conditions.

The PSP technique was successfully used to determine flowfield periodicity for steady state conditions in the transonic flutter cascade. Fig. 16 shows the PSP apparatus in front of the cascade. As seen here, the cascade is provided with three windows in the front wall. The back wall was painted with PSP. The results of the experiment are summarized in Fig. 17. The figure illustrates the periodicity of the cascade flowfield for an inlet Mach number of 1.3. A shadowgraph picture of the cascade shock structure is accompanied by a sidewall static pressure field acquired using the technique of pressure sensitive paint. It can be observed here that a periodic shock structure is in a flowfield which exhibits an overall positive pressure gradient in the pitchwise direction from the left end of the cascade to the right. The increasing pressure gradient across the cascade is manifested by decreasing relative depth of wall pressure depressions above the blades just past the blade leading edges.

The pressure field on the suction surface is of great interest in these tests. As mentioned above the blades are very thin and it is difficult to instrument them even with conventional static taps for pressure data acquisition at steady state conditions at more than few points. At present, an effort is being carried out to use PSP technique for such measurements. The test apparatus is in Fig 18. Only the middle blade is painted with PSP on its upper (suction)

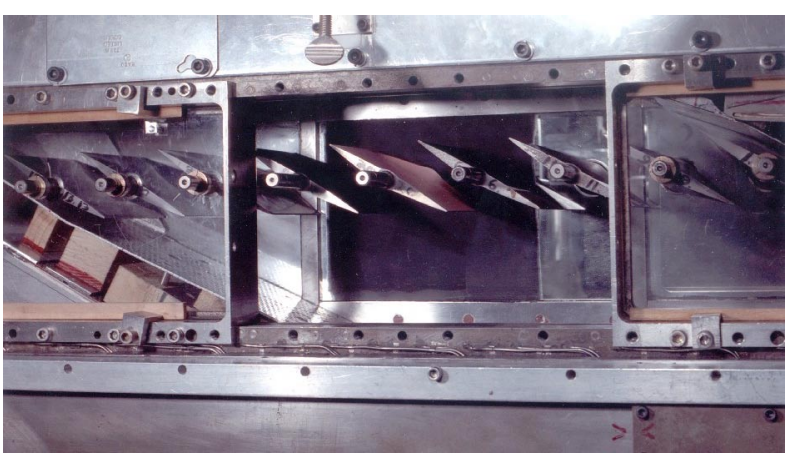

Fig. 15 NASA transonic flutter cascade.

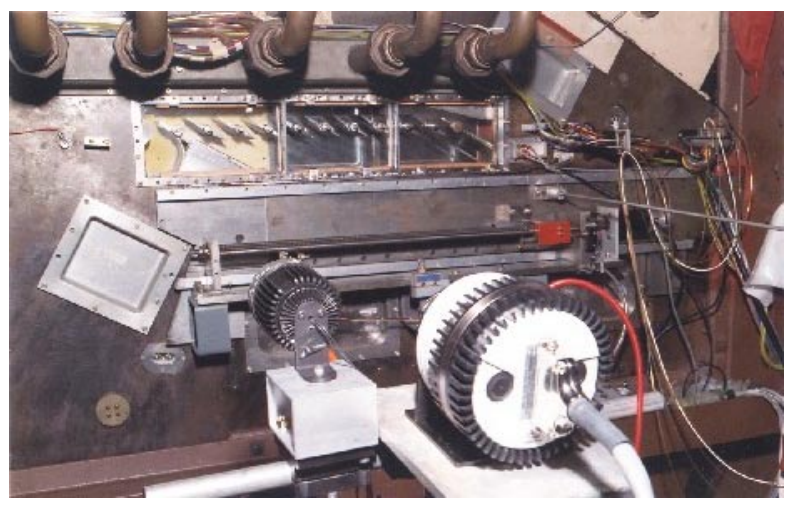

Fig. 16 PSP test apparatus in front of the transonic flutter cascade.

surface. The CCD camera (upper left corner in the foreground) is coupled to a fiber optics periscope (a rod protruding from above the cascade window toward the camera) that will allow observation of the blade surface under a viewing angle that deviates only a little from the desired perpendicular direction. Data from this experiment are being analyzed and are not yet available for publication.

\section{Conclusions}

Valuable experience was gained from the application of the PSP technique to measurements in internal flows with shock waves and turbomachinery flows. The results show that this nonintrusive experimental technique can be successfully used in turbomachinery research for steady state conditions at present. The results achieved indicate the potential of the PSP technique for acquiring pressure field data efficiently, particularly for offdesign operating conditions where analytical predictions are not always available. On the other hand, the problems encountered show that a lot of work still needs to be done to bring the accuracy of the PSP data to the level required for reliable code verification and refinement. The areas that will require special attention are mainly effects of internal reflections and flow temperature on the PSP calibration methodology. Next, the problems of paint erosion and 


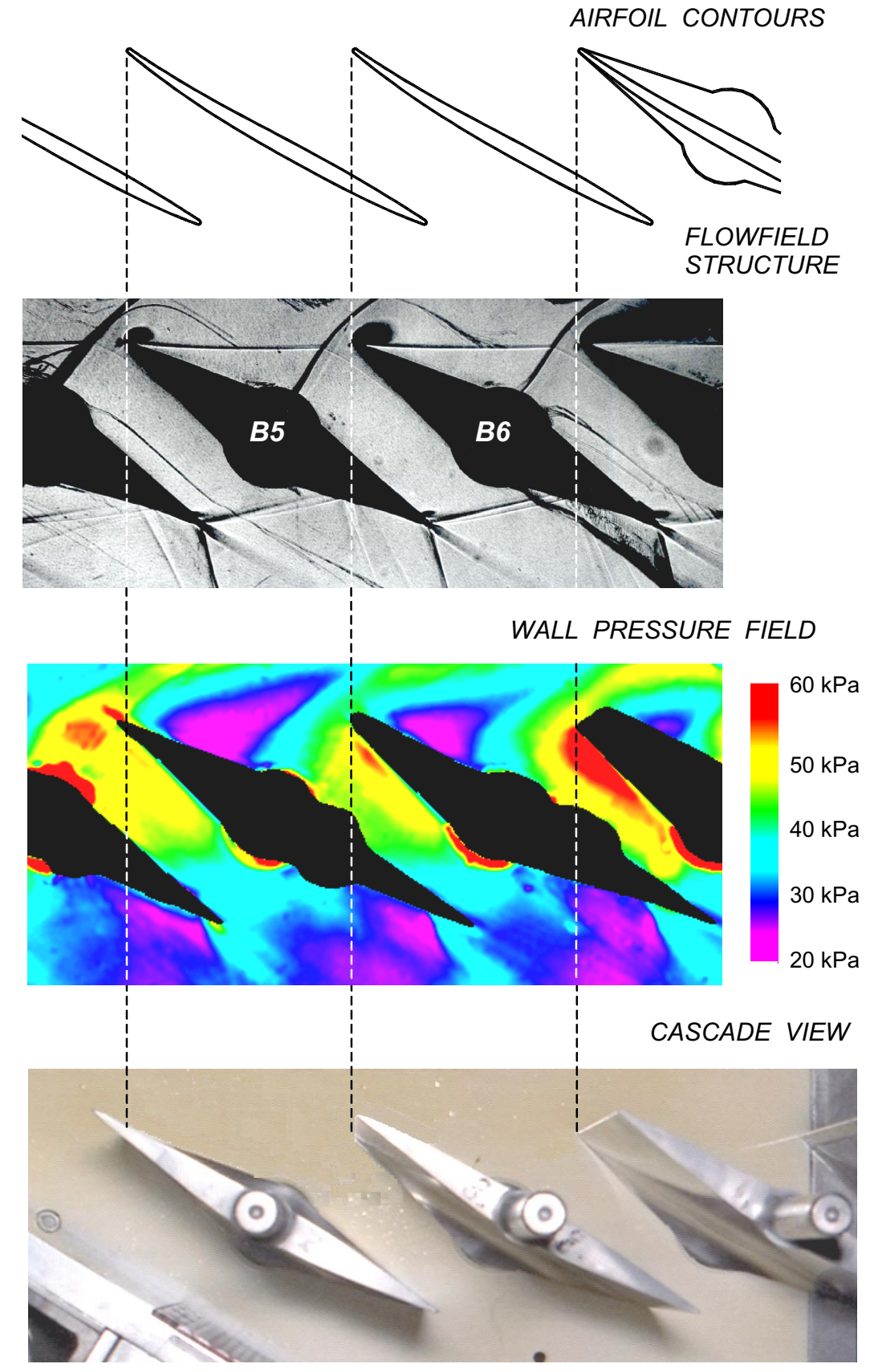

Fig. 17 Cascade flowfield for Mach number 1.3.

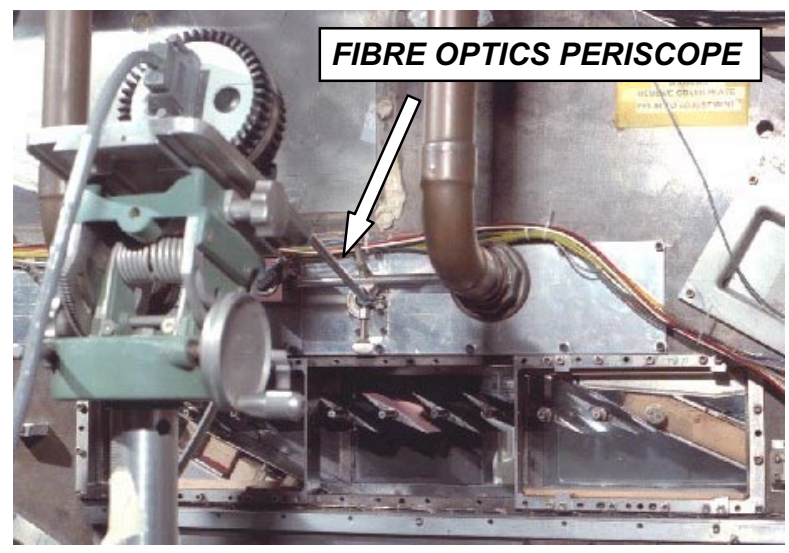

Fig. 18 CCD camera with fibre optics periscope. 
adhesion should be addressed. Finally, suitable changes in test facilities (better optical access ports - fiber optic applica-tion, flow filtering, and oil leakage) should be considered and implemented for future PSP experiments.

\section{References}

1. Crites, R.C.: "Pressure Sensitive Paint Technique", VKI Lecture Series, VKI LS 1993-05, 1993.

2. McLachlan, B.G., Kavandi, J.B., Callis J., Gouterman, M., Khalil, G., and Burns, D.: "Surface pressure field mapping using luminescent coatings", Experiments in Fluids, Vol. 14, pp. 33-41, 1993.

3. Bell, J.H., Schairer, E.T., Hand, L.A., and Mehta, R.D.: "Surface Pressure Measurements Using Luminescent Coatings", Annual Reviw of Fluid Mechanics, Vol. 33, pp. 155-206, 2001.

4. Morris, M.J. and Donovan, J.F.: "Application of Pressure- and Temperature Sensitive Paints to HighSpeed Flows", Paper AIAA 94-2231, 1994.

5. Liu, T., Johnston, R., Torgerson, S., Fleeter, S., and Sullivan, J.: "Rotor Blade Pressure Measurement in a High Speed Axial Compressor Using Pressure and Temperature Sensitive Paints", Paper AIAA 97-0162, 1997.

6. Navarra, K., Goss, L., Jordan, J., Rabe, D., Gord, J., and Car, D.: "Optical Measurements of Surface Pressure and Temperature in Turbomachinery", Paper \#18, Advanced Non-Intrusive Instrumentation for Propulsion Engines, Brussels, 1997.

7. Bencic, T.J.: "Rotating Pressure and Temperature Measurements on Scale-model Fans Using Luminescent Paints", Paper AIAA 98-3452, 1998.
8. Taghavi, R., Raman, G., and Bencic, T.J.: "Pressure sensitive paint demonstrates relationship between ejector wall pressure and aerodynamic performance", Experiments in Fluids, Vol. 16, pp. 481-487, 1999.

9. Bencic, T.J.: "Calibration of Detection Angle for Full Field Pressure-Sensitive Paint Measurements", Paper AIAA 2001-0307, 2001.

10. Bruckner, R.J. and Lepicovsky, J.: "A Supersonic Tunnel for Laser and Flow Seeding Techniques", NASA TM-106588, 1994; also AIAA Paper 94-1824, 1994

11. Lepicovsky, J. and Bruckner, R.J.: "Seeding for Laser Velocimetry in Confined Supersonic Flows with Shocks", NASA TM-107265, 1996.

12. Lepicovsky, J., Bencic, T.J., and Brucker, R.J.: "Application of Pressure Sensitive Paint to Confined Flow at Mach Number 2.5", AIAA Paper 97-3214, 1997.

13. Lepicovsky, J., Brucker, R.J, Bencic, T.J., and Braunscheidel, E.P.: "Modern Experimental Techniques in Turbine Engine Testing", International Journal of Turbo and Jet Engines, Vol. 16, pp. 61-70, 1999, also NASA TM 107383, 1996.

14. Lepicovsky, J.: "PSP Measurement of Stator Vane Surface Pressures in a High Speed Fan", NASA CR1998-207403, 1998.

15. Lepicovsky, J., McFarland, E.R., Chima, R.V., and Wood, J.R.: "On Flow Periodicity in the NASA Transonic Flutter Cascade, Part I - Experimental Study", Paper ASME 2000-GT-0572, 2000, also NASA TM-2000-209934, 2000. 
Public reporting burden for this collection of information is estimated to average 1 hour per response, including the time for reviewing instructions, searching existing data sources, gathering and maintaining the data needed, and completing and reviewing the collection of information. Send comments regarding this burden estimate or any other aspect of this collection of information, including suggestions for reducing this burden, to Washington Headquarters Services, Directorate for Information Operations and Reports, 1215 Jefferson Davis Highway, Suite 1204, Arlington, VA 22202-4302, and to the Office of Management and Budget, Paperwork Reduction Project (0704-0188), Washington, DC 20503.

\begin{tabular}{|l|l|l}
\hline 1. AGENCY USE ONLY (Leave blank) & $\begin{array}{c}\text { 2. REPORT DATE } \\
\text { November } 2001\end{array}$ & $\begin{array}{r}\text { 3. REPORT TYPE AND DATES COVERED } \\
\text { Technical Memorandum }\end{array}$ \\
\hline
\end{tabular}

\section{TITLE AND SUBTITLE}

Use of Pressure Sensitive Paint for Diagnostics in Turbomachinery

Flows With Shocks

6. AUTHOR(S)

Jan Lepicovsky and Timothy J. Bencic

7. PERFORMING ORGANIZATION NAME(S) AND ADDRESS(ES)

National Aeronautics and Space Administration

John H. Glenn Research Center at Lewis Field

Cleveland, Ohio 44135-3191
5. FUNDING NUMBERS

WU-708-28-13-00

8. PERFORMING ORGANIZATION

REPORT NUMBER

E-12958

\section{SPONSORING/MONITORING AGENCY NAME(S) AND ADDRESS(ES)}

National Aeronautics and Space Administration

Washington, DC 20546-0001
10. SPONSORING/MONITORING AGENCY REPORT NUMBER

NASA TM-2001-211111

ISABE 2001-1142

\section{SUPPLEMENTARY NOTES}

Prepared for the 15th International Symposium on Airbreathing Engines sponsored by the International Society for Airbreathing Engines, Bangalore, India, September 2-7, 2001. Jan Lepicovsky, QSS Group, Inc., 2000 Aerospace Parkway, Brook Park, Ohio 44142; Timothy J. Bencic, NASA Glenn Research Center. Responsible person,

Timothy J. Bencic, organization code 5420, 216-433-5690.

12a. DISTRIBUTION/AVAILABILITY STATEMENT

12b. DISTRIBUTION CODE

Unclassified - Unlimited

Subject Category: 07

Distribution: Nonstandard

Available electronically at http://gltrs.grc.nasa.gov/GLTRS

This publication is available from the NASA Center for AeroSpace Information, 301-621-0390.

13. ABSTRACT (Maximum 200 words)

The technology of pressure sensitive paint (PSP) is well established in external aerodynamics. In internal flows in narrow channels and in turbomachinery cascades, however, there are still unresolved problems. In particular, the internal flows with complex shock structures inside highly curved channels present a challenge. It is not always easy and straightforward to distinguish between true signals and 'ghost' images due to multiple internal reflections in narrow channels. To address some of the problems, investigations were first carried out in a narrow supersonic channel of Mach number 2.5. A single wedge or a combination of two wedges were used to generate a complex shock wave structure in the flow. The experience gained in a small supersonic channel was used for surface pressure measurements on the stator vane of a supersonic throughflow fan. The experimental results for several fan operating conditions are shown in a concise form, including performance map points, midspan static tap pressure distributions, and vane suction side pressure fields. Finally, the PSP technique was used in the NASA transonic flutter cascade to compliment flow visualization data and to acquire backwall pressure fields to assess the cascade flow periodicity. A summary of shortcomings of the pressure sensitive paint technology for internal flow application and lessons learned are presented in the conclusion of the paper.

14. SUBJECT TERMS

Pressure sensitive paint; Turbomachinery 15

\begin{tabular}{|c|c|c|}
\hline $\begin{array}{c}\text { 17. SECURITY CLASSIFICATION } \\
\text { OF REPORT } \\
\text { Unclassified }\end{array}$ & $\begin{array}{c}\text { 18. SECURITY CLASSIFICATION } \\
\text { OF THIS PAGE } \\
\text { Unclassified }\end{array}$ & $\begin{array}{c}\text { 19. SECURITY CLASSIFICATION } \\
\text { OF ABSTRACT } \\
\text { Unclassified }\end{array}$ \\
\hline
\end{tabular}

